\title{
The impact of pharmacist-managed clinic on medication adherence and health-related quality of life in patients with COPD: a randomized controlled study
}

\author{
This article was published in the following Dove Press journal: \\ Patient Preference and Adherence \\ II July 2016 \\ Number of times this article has been viewed
}

\section{Chuanwei Xin \\ Zhongni Xia \\ Cheng Jiang \\ Mengmeng Lin \\ Gonghua Li}

Department of Pharmacy, Zhejiang Academy of Traditional Chinese

Medicine, Tongde Hospital of Zhejiang Province, Hangzhou, People's Republic of China
Correspondence: Gonghua Li Department of Pharmacy, Zhejiang Academy of Traditional Chinese Medicine, Tongde Hospital of Zhejiang Province, Gucui Road 234 of Hangzhou, People's Republic of China

Tel +8657I 89972240

Email xyaoshi9@163.com
Introduction: COPD is rapidly becoming one of the most challenging health problems worldwide, which is characterized by not fully reversible airflow limitation. Although a lot of treatment medications have been delivered, the treatment goals of COPD are often not achieved. Furthermore, few well-designed randomized controlled trials in the People's Republic of China have been reported to evaluate the impact of pharmacist-managed clinic (PMC) on medication adherence and health-related quality of life in patients with COPD.

Methods: A prospective randomized controlled study (on a PMC group and a control group) was conducted between January 2015 and December 2015. A structured education about COPD was provided by a clinical pharmacist to the PMC group. Primary outcomes were medication adherence (assessed by medication refill adherence scores) and health-related quality of life (assessed by St George's Respiratory Questionnaire). Secondary outcomes were exacerbation rate, hospitalization rate, and smoking behavior.

Results: A total of 244 patients were enrolled for our study. The PMC group showed a significantly greater improvement in medication adherence compared with the baseline $(93.1 \pm 14.2 \mathrm{vs}$ $78.8 \pm 12.3, P<0.01)$. When compared with the control group, there were more patients whose medication refill adherence score was $\geq 80$ in the PMC group ( $83.3 \%$ vs $51.3 \%, P<0.01)$. The total St George's Respiratory Questionnaire scores was found to be improved significantly in the PMC group $(42.7 \pm 3.2$ vs $52.4 \pm 5.2, P<0.05)$. There was a lower hospitalization rate in the PMC group, and more patients in the PMC group quit smoking $(71.0 \%$ vs $52.2 \%, P<0.05)$.

Conclusion: The PMC may result in improvement of medication adherence and the healthrelated quality of life in patients with COPD. In the PMC group, a significant reduction in exacerbation rate, hospitalization rate, and smoking behavior was observed; therefore, our study provides support for a greater involvement of PMC in the care of patients with COPD.

Keywords: COPD, pharmacist-managed clinic, medication adherence, St George's Respiratory Questionnaire, smoking status

\section{Introduction}

COPD is a common disease of respiratory system, which is characterized by non-fully reversible airflow obstruction. Acute exacerbations of COPD are important drivers of mortality and reduced quality of life in COPD patients and are the second most common reason for emergency hospital admission. According to a research published by the World Health Organization, ${ }^{1}$ COPD has become the fourth leading cause of mortality in the US. It is estimated to become the fifth leading cause of disease burden in 2020 . 
In the People's Republic of China, the prevalence of COPD has been estimated at $8.2 \%$ among people aged 40 years. ${ }^{2}$ COPD has thus become an important global health problem.

In order to administrate COPD effectively, the Global Initiative for Chronic Obstructive Lung Disease (GOLD) updates its guidelines for diagnosis, management, and prevention every year. ${ }^{3}$ The Chinese version of COPD guidelines $^{4}$ is formulated based on the GOLD guidelines. As an important part of the management of stable COPD, the Chinese guidelines recommend the pharmacotherapy of patients be monitored closely, especially the medication adherence. Although the acute exacerbations of COPD are potentially preventable by suitable drug, it is very difficult for the patients to follow the prescribed regimens. There are many patients with COPD who cannot take drugs as prescribed or visit their physician. 5,6

Some systematic reviews have demonstrated that the pharmaceutical care may improve the health outcomes of patients with cardiovascular diseases ${ }^{7}$ and diabetes mellitus. ${ }^{8}$ However, in the People's Republic of China, treatment for COPD is mainly provided by doctors or nurses, while clinical pharmacist involved occasionally. It was not until 2007 that the clinical pharmacy began to attain long-term development. In the pharmaceutical affairs management of medical institutions, five full-time clinical pharmacists are indispensable. Now, the roles of pharmacists have been expanded from dispensing prescriptions to providing pharmaceutical services to patients; these services include managing medication therapy, distributing educational materials, and monitoring the adverse drug reaction (ADR). COPD has been described as requiring 10\% medication and 90\% education. To the best of our knowledge, few well-designed clinical trials in the Zhejiang Province of the People's Republic of China have been reported to evaluate the effectiveness of pharmacist-managed clinic (PMC) on medication adherence and health-related quality of life. The aim of this prospective randomized controlled study was to assess the impact of PMC on medication adherence and health-related quality of life in COPD patients.

\section{Methods}

\section{Design and setting}

We conducted a prospective randomized controlled study between January 2015 and December 2015. Patients were recruited from Tongde Hospital of Zhejiang Province, which is located in the Hangzhou City of the Zhejiang Province.

Inclusion criteria for patients included 1) age $\geq 35$ years, 2) diagnosis of COPD, 3) regular visit to the pharmacist, 4) no previous diagnosis of uncontrolled psychiatric disease, and
5) no previous diagnosis of severe liver or kidney disease. Patients who were pregnant or analphabetic were excluded. Eligible patients were randomly assigned to either the PMC group or the control group. The randomization codes were generated by computer, and the clinical pharmacist was blinded to it.

In accordance with the GOLD guidelines, the patient's adherence to maintenance therapy and the scores of St George's Respiratory Questionnaire (SGRQ) were chosen as primary outcomes. Secondary outcomes were the acute exacerbation rate, hospitalization rate due to acute exacerbation, and smoking behavior. Adherence was assessed by medication refill adherence (MRA) ${ }^{9,10}$ score. The MRA score was calculated by the formula: the number of participation days/total number of days; the number of participation days was the period from the beginning date of the study to the date of second clinic visit. If the MRA score was $\geq 80$, the patient was considered adherent. ${ }^{11}$ The MRA was periodically assessed every 12 months. The SGRQ score is a supervised, self-managed measure, designed specifically for patients with chronic airways disease. The SGRQ has been validated to evaluate the health impairment and responsiveness to therapy in patients with chronic airflow limitation. It has 50 items, divided into three domains: impacts, activities, and symptoms. ${ }^{12}$ For each domain, the score is from 0 to 100 . The lowest score indicated that there was no effect on life completely, and a score of 100 indicated the poorest respiratory health of the patient. A change in the mean score of 4 units has been validated as a clinically significant threshold. ${ }^{13,14}$ The SGRQ score was periodically reassessed every 6 months.

The smoking status of patients was assessed through a questionnaire at the beginning and the end of this study, which included the following questions: Did you ever smoke?; How long did you smoke?; How many cigarettes do you smoke every day?; Do you still smoke now?; Are you trying to quit?; and Why did you cannot quit smoke?

\section{Ethical approval}

After approval by the research review committee from Tongde Hospital of Zhejiang Province, and written informed patient consent was obtained, we began to design the study.

\section{Pharmacist-managed clinic}

To maximize the efficacy and minimize the adverse drug events, the first PMC in the Zhejiang Province was established for respiratory therapy at Tongde Hospital of Zhejiang Province in January 2015. The PMC was opening on Wednesday every week. The pharmacist was mainly responsible for individualized education, and developing a 
comprehensive pharmaceutical care program. The patients in the control group received the usual care delivered by the doctor, but did not receive prescription services by the clinical pharmacist.

Patients in the PMC group were individually educated. At first, the pharmacist discussed with the patients about the definition of COPD, pathophysiology of the disease, the importance of medication adherence, and the importance of smoking cessation. Then, the pharmacist taught the patients on how to take the prescribed drugs and use the respiratory devices effectively, explained the possible ADR, the possible effect of drug combination, the importance of a well-balanced diet with sufficient intake of fresh fruits and vegetables, and the necessity of timely follow-up by physicians. At last, the pharmacist shared his phone number for the patients to consult conveniently. In order to help the patients understand easily the education plan, the pharmacist prepared many drug education materials, ${ }^{14-16}$ especially on how to use the inhaled device, and the patients were allowed to take it to their home.
During telephone or network (eg, WeChat) counseling, the pharmacist asked the patients about the effect of medication, explained the examination results, the possible ADR, and reminded when the patients should visit their doctor.

All of the patient's data including sex, age, diagnosis, and drugs used were entered into SPSS Version 19.0 (IBM Corporation, Armonk, NY, USA) for statistical analysis. The characteristics of patients in the PMC group and the control group were compared using chi-square tests. A $P$-value of $<0.05$ was considered statistically significant.

\section{Results}

During the 12 months of the study, 499 patients were prescreened, of whom 336 were found eligible. Sixty-one percent $(n=244)$ of patients agreed to participate, and were assigned randomly to the PMC group $(n=122)$ or the control group $(n=122)$. Almost 93\% $(n=227)$ of patients completed this study. The flow chart of inclusion and exclusion of patients is shown in Figure 1.

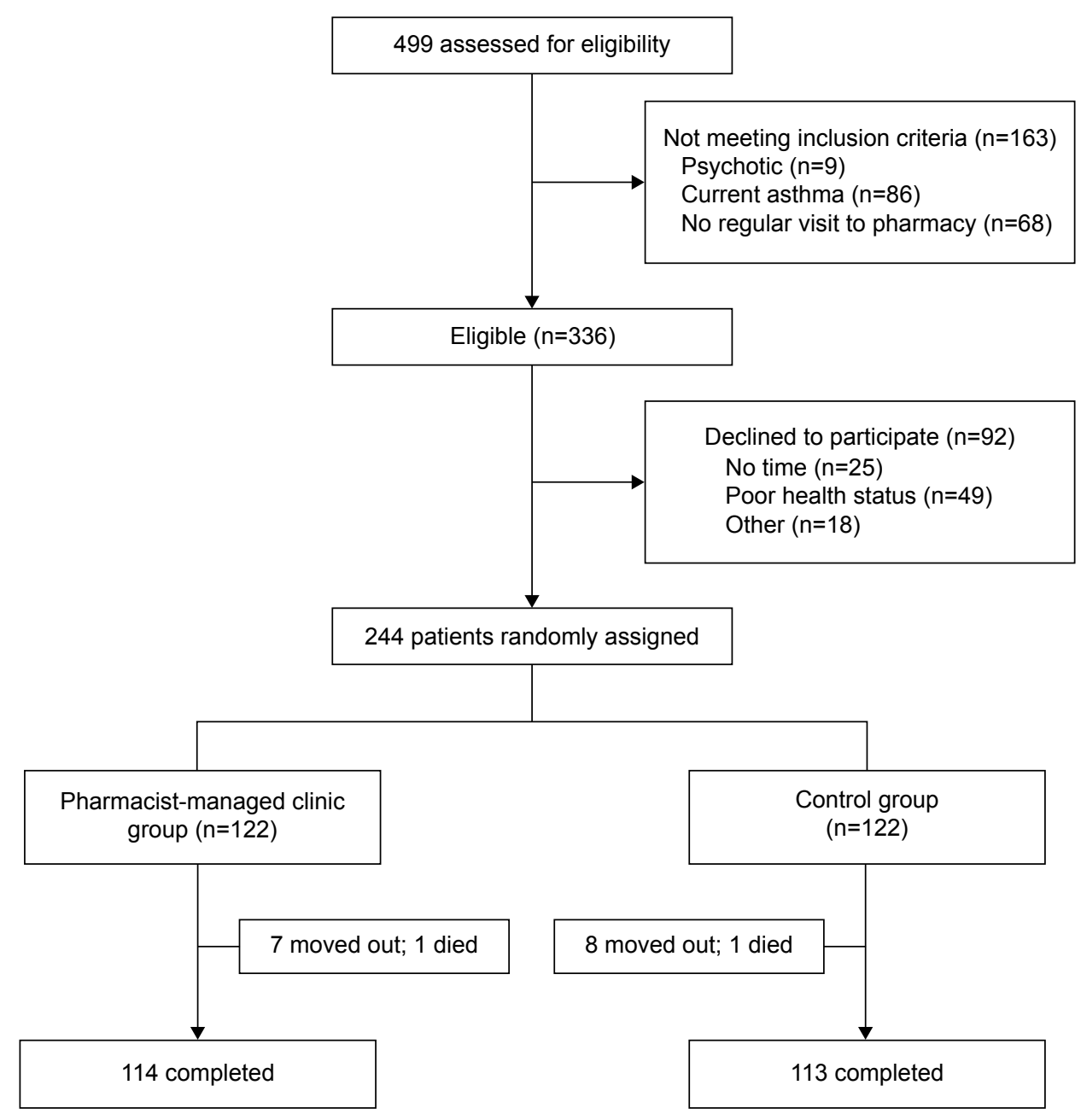

Figure I Flow of participants through the study. 
Table I Patient demographics and clinical characteristics at baseline

\begin{tabular}{|c|c|c|c|}
\hline Demographic & $\begin{array}{l}\text { PMC group } \\
(n=|| 4)\end{array}$ & $\begin{array}{l}\text { Control group } \\
(n=|| 3)\end{array}$ & $P$-value \\
\hline Age, mean \pm SD (range) (years) & $64.2 \pm 14.2$ & $64.6 \pm 14.5$ & 0.178 \\
\hline Sex, n (\%) & & & 0.043 \\
\hline Male & $44(38.6)$ & $42(37.1)$ & \\
\hline Female & $70(61.4)$ & $71(62.8)$ & \\
\hline Mean body mass index $(\mathrm{SD})\left(\mathrm{kg} / \mathrm{m}^{2}\right)$ & $27.9 \pm 1.5$ & $28.1 \pm 1.8$ & 0.637 \\
\hline Current smokers, n (\%) & $85(74.5)$ & $84(74.3)$ & 0.949 \\
\hline Education, n (\%) & & & 0.825 \\
\hline High (university) & $35(30.7)$ & $32(28.3)$ & \\
\hline Low & 79 (69.3) & $81(71.6)$ & \\
\hline Marital status, n (\%) & & & 0.924 \\
\hline Married & $112(98.2)$ & $112(99.1)$ & \\
\hline Other & $2(1.7)$ & $\mathrm{I}(0.8)$ & \\
\hline Living arrangements, n (\%) & & & 0.982 \\
\hline Alone & $22(19.3)$ & $22(19.4)$ & \\
\hline Not alone & $92(80.7)$ & $91(80.5)$ & \\
\hline $\mathrm{FEV}_{1}$, mean $\pm \mathrm{SD}$ & & & 0.815 \\
\hline$\%$ predicted & $55.4 \pm 15.7$ & $54.7 \pm 14.9$ & \\
\hline $\mathrm{FEV}_{1} / \mathrm{FVC}$ & $51.5 \pm 9.2$ & $50.8 \pm 8.8$ & \\
\hline Duration of COPD, mean \pm SD (years) & $11.5 \pm 9.3$ & $10.8 \pm 9.1$ & 0.842 \\
\hline Number of COPD medications, mean \pm SD & $6.4 \pm 1.0$ & $6.2 \pm 1.0$ & 0.904 \\
\hline Number of hospital admissions (last 12 months) & 73 & 71 & 0.957 \\
\hline Comorbid conditions, $\mathrm{n}(\%)$ & $84(73.6)$ & $85(75.2)$ & 0.822 \\
\hline
\end{tabular}

Abbreviations: PMC, pharmacist-managed clinic; SD, standard deviation; FEV ${ }_{1}$, forced expiratory volume in I second; FVC, forced vital capacity.

There were similar clinical characteristics and sociodemographics between the study participants at baseline (Table 1). Most patients were elderly, females, married, and of low educational status. Mean age of the study population was $64.2 \pm 14.2$ years in the PMC group and $64.6 \pm 14.5$ years in the control group. More than half of the patients were found to have different comorbidities, such as diabetes and hypertension. The treatment medications were similar between two groups. Most of the patients were suffering from moderate or severe COPD, with a mean forced expiratory volume in $1 \mathrm{~second} /$ forced vital capacity of 54\%. There was no significant difference in the number of hospital admissions at baseline between the two groups.
During the study, the patients in the PMC group and the control group were offered appropriate treatment medications (Table 2). At the baseline, mean MRA scores were $78.8 \pm 12.3$ in the PMC group and 77.4 \pm 12.2 in the control group. After the trial, a significantly greater MRA scores in the PMC group were detected ( $93.1 \pm 14.2$ vs $78.8 \pm 12.3, P<0.01)$, compared with the baseline. Additionally, when compared with the control group, there was a significant increase of patients whose MRA scores was $\geq 80$ in the PMC group ( $83.3 \%$ vs $51.3 \%, P<0.01$; Table 3 ).

At the baseline, the patients in both the PMC group and the control group were found to have approximately similar scores in SGRQ (50.9 \pm 4.7 vs $50.6 \pm 4.6, P=0.949)$.

Table 2 Prescribed medications for COPD in the PMC and control group patients

\begin{tabular}{llllll}
\hline $\begin{array}{l}\text { Prescribed } \\
\text { medication }\end{array}$ & Baseline & & & I 2-month treatment \\
\cline { 2 - 3 } \cline { 5 - 6 } & PMC group, $\mathbf{n}(\%)$ & Control group, $\mathbf{n}(\%)$ & & PMC group, $\mathbf{n}(\%)$ & Control group, $\mathbf{n}(\%)$ \\
\hline SABA & $55(45.0)$ & $54(44.2)$ & $51(44.7)$ & $49(43.3)$ \\
LABA/ICS & $58(47.5)$ & $15(12.3)$ & $68(59.6)$ & $64(56.6)$ \\
LABA & $14(11.4)$ & $62(50.8)$ & $17(14.9)$ & $16(14.2)$ \\
LAMA & $63(51.6)$ & $9(7.4)$ & $84(73.6)$ & $81(71.6)$ \\
Oral steroids & $7(5.7)$ & $35(28.6)$ & $8(7.0)$ & $5(4.4)$ \\
Anticholinergic agents & $32(26.2)$ & $25(20.4)$ & $37(32.4)$ & $38(33.6)$ \\
Xanthines & $22(18.0)$ & & $24(21.0)$ & $25(19.4)$ \\
P-value & 0.74 & 0.63 & \\
\hline
\end{tabular}

Abbreviations: PMC, pharmacist-managed clinic; SABA, short-acting $\beta_{2}$ agonist; LABA, long-acting $\beta_{2}$ agonist; ICS, inhaled corticosteroid; LAMA, long-acting muscarinic antagonist. 
Table 3 Medication adherence in the PMC and control group over the 12-month assessment period

\begin{tabular}{|c|c|c|c|}
\hline $\begin{array}{l}\text { Adherence to } \\
\text { maintenance medication }\end{array}$ & $\begin{array}{l}\text { PMC } \\
\text { group }\end{array}$ & $\begin{array}{l}\text { Control } \\
\text { group }\end{array}$ & $P$-value \\
\hline \multicolumn{4}{|l|}{ MRA score, mean \pm SD } \\
\hline Baseline & $78.8 \pm 12.3$ & $77.4 \pm 12.2$ & 0.798 \\
\hline 12-month intervention & $93.1 \pm 14.2$ & $83.2 \pm 12.7$ & 0.003 \\
\hline \multicolumn{4}{|c|}{ No of patients with MRA $\geq 80, n$ (\%) } \\
\hline Baseline & 63 & 61 & 0.904 \\
\hline 12-month intervention & 95 (83.3\%) & $58(5 \mathrm{I} .3 \%)$ & 0.002 \\
\hline
\end{tabular}

Abbreviations: PMC, pharmacist-managed clinic; MRA, medication refill adherence; $\mathrm{SD}$, standard deviation.

After 12 months, the total SGRQ scores improved significantly after the PMC intervention ( $42.7 \pm 3.2$ vs $52.4 \pm 5.2, P<0.05$ ), and the scores of the domains of symptoms, activities, and impacts in the PMC group were significantly improved, as shown in Table 4 . The best improvement was noted in the impacts domain $(30.8 \pm 2.4$ vs $43.2 \pm 5.4, P<0.05)$.

During the study, there were 51 independent acute exacerbations reported. Compared with 16 in the PMC group, 35 acute exacerbations were observed in the control group. Any exacerbation requiring an emergency department visit or hospitalization was regarded as severe, and there were significantly lower number of patients in the PMC group who had a severe exacerbation ( 14 vs $28, P=0.024$ ). In addition, there were fewer hospitalizations in the PMC group (11 vs 35, $P=0.015)$. At the beginning of this study, $\sim 74 \%$ of patients self-reported to smoke, but after the trial, 83 (71\%) patients

Table 4 Changes in SGRQ scores at different time assessments

\begin{tabular}{|c|c|c|c|}
\hline SGRQ scores & $\begin{array}{l}\text { PMC } \\
\text { group, } \\
\text { mean } \pm \text { SD }\end{array}$ & $\begin{array}{l}\text { Control } \\
\text { group, } \\
\text { mean } \pm \text { SD }\end{array}$ & $P$-value \\
\hline \multicolumn{4}{|l|}{ Total score } \\
\hline Baseline & $50.9 \pm 4.7$ & $50.6 \pm 4.6$ & 0.949 \\
\hline After 6 months of treatment & $47.2 \pm 4.6$ & $49.2 \pm 4.4$ & 0.618 \\
\hline After 12 months of treatment & $42.7 \pm 3.2$ & $52.4 \pm 5.2$ & 0.024 \\
\hline \multicolumn{4}{|l|}{ Symptoms } \\
\hline Baseline & $47.9 \pm 4.4$ & $47.4 \pm 4.2$ & 0.924 \\
\hline After 6 months of treatment & $40.2 \pm 2.7$ & $46.8 \pm 4.5$ & 0.227 \\
\hline After 12 months of treatment & $38.2 \pm 2.2$ & $44.2 \pm 3.8$ & 0.028 \\
\hline \multicolumn{4}{|l|}{ Activities } \\
\hline Baseline & $53.2 \pm 4.9$ & $54.6 \pm 4.6$ & 0.835 \\
\hline After 6 months of treatment & $47.6 \pm 3.2$ & $56.6 \pm 4.7$ & 0.427 \\
\hline After 12 months of treatment & $42.3 \pm 2.5$ & $50.2 \pm 2.7$ & 0.025 \\
\hline \multicolumn{4}{|l|}{ Impacts } \\
\hline Baseline & $43.2 \pm 5.4$ & $44.6 \pm 5.1$ & 0.822 \\
\hline After 6 months of treatment & $35.7 \pm 2.9$ & $45.8 \pm 5.5$ & 0.424 \\
\hline After 12 months of treatment & $30.8 \pm 2.4$ & $42.8 \pm 2.3$ & 0.024 \\
\hline
\end{tabular}

Abbreviations: SGRQ, St George's Respiratory Questionnaire; PMC, pharmacistmanaged clinic; SD, standard deviation.
Table 5 Severe exacerbations, hospitalizations, and smoking status over the 12 months

\begin{tabular}{|c|c|c|c|}
\hline $\begin{array}{l}\text { Severe exacerbations, } \\
\text { hospitalizations, } \\
\text { and smoking status }\end{array}$ & $\begin{array}{l}\text { PMC } \\
\text { group, } \\
\mathrm{n}=114\end{array}$ & $\begin{array}{l}\text { Control } \\
\text { group, } \\
\mathrm{n}=1 \mathrm{I} 3\end{array}$ & $P$-value \\
\hline \multicolumn{4}{|l|}{ Severe exacerbations } \\
\hline Patients with event, $\mathrm{n}(\%)$ & $14(12.2)$ & $28(24.7)$ & 0.024 \\
\hline Total events (n) & 16 & 35 & \\
\hline \multicolumn{4}{|l|}{ Hospitalizations } \\
\hline Patients with event, n (\%) & $9(7.8)$ & $24(21.2)$ & 0.015 \\
\hline Total hospitalizations (n) & 11 & 35 & \\
\hline $\begin{array}{l}\text { Duration of hospitalization, } \\
\text { mean } \pm \text { SD (days) }\end{array}$ & $8.1 \pm 2.2$ & $14.2 \pm 2.8$ & 0.042 \\
\hline \multicolumn{4}{|l|}{ Current smokers } \\
\hline After 12 months, $\mathrm{n}(\%)$ & $4(3.5)$ & $25(22.1)$ & 0.022 \\
\hline Quit smoking, n (\%) & $81(71.0)$ & $59(52.2)$ & \\
\hline
\end{tabular}

Note: Exacerbations requiring an emergency department visit or hospitalization were regarded as severe.

Abbreviations: PMC, pharmacist-managed clinic; SD, standard deviation

in the PMC group and 59 (52.2\%) patients in the control group quit smoking, as shown in Table 5.

\section{Discussion}

In this study, we assessed the effectiveness of PMC in 244 patients with COPD. The main outcomes were selected based on GOLD guidelines and the disease management. The PMC significantly improved medication adherence, and scores of SGRQ and its subscales (symptoms, activities, and impacts), and decreased severe exacerbation and hospitalization rate.

Based on our study data, a significant difference between the two groups in medication adherence after 12 months was noted, which was most likely attributed to the intensive education received from a clinical pharmacist by the PMC group. This is consistent with a 12-month study of Khdour et $\mathrm{a}^{10}$ in Northern Ireland, as the findings showed that clinical pharmacist-led education for patients with COPD led to a significant improvement in medication adherence. Therefore, positive health education can improve medication adherence of patients with COPD. A clinical pharmacist is well placed in the health care team to act as a link between the physicians and the patients.

With progression, COPD undoubtedly affects the ability of patients to perform normal daily activities, thereby affecting their quality of life. ${ }^{17}$ As shown in Table 4, patients demonstrated a similar SGRQ scores at the baseline; however, SGRQ scores in the PMC group improved significantly after the trial. The findings of this present study on improved SGRQ scores in patients with COPD were inconsistent with those of Jordan et al ${ }^{18}$ for instance, the 
baseline mean scores on SGRQ for the patients in Jordan's research were 36.8 , which indicated that the patients may have had a good health status. In our study, the mean score on SGRQ was 50.9; therefore, the patients have had a poor quality of life, so there was a bigger margin for the patients to improve.

The reduction in severe exacerbations and hospitalization rate was another significant improvement in the present study. Since acute exacerbation of COPD can not only destroy health status, but also fasten the progression of disease, ${ }^{19}$ it was an important treatment target for pharmacist intervention. ${ }^{20}$ Some study demonstrated an education plan for reduction in hospitalization rate, ${ }^{21}$ but the researchers emphasized usage of antibiotic and corticosteroid besides pharmacist interventions. In this present clinical trial, the reduction in hospital admissions may be attributable to the reduction in acute exacerbation.

The People's Republic of China has been the world's largest cigarette consumer and producer. It was directly beneficial for a patient to quit smoking, During this study, the motivation for smoking cessation for people with mild COPD was not strong, while the smoking cessation methods based on PMC intervention were effective for patients with moderate and severe COPD.

\section{Limitations}

While the present study has a number of methodological strengths, it has several limitations. This study utilized data from a single-center and was performed for a short term; therefore, our patients may not represent the general population of patients with COPD. Furthermore, there was not a gold standard to measure adherence; some methods are useful in daily practice (fast, easy, and cheap to apply), but may overestimate adherence. ${ }^{22}$ And because some clinical trials are often accepted more frequently for motivating patients, the selection bias may not be fully excluded, which may affect the results.

\section{Conclusion}

This study was demonstrated to evaluate the impact of PMC on a wide range of clinical outcomes in patients with COPD. Both primary outcomes, that is, medication adherence and SGRQ scores on symptom and impact, were significantly improved in the PMC group. A trend toward reduction in severe exacerbations, hospitalization rate, and smoking status was also observed. To improve health-related quality of life in patients with COPD, our study clearly demonstrated the effectiveness of implementing a PMC in the People's Republic of China. Clinical pharmacist can be a good support to the doctor in the management of patients with COPD.

\section{Acknowledgments}

The authors would like to acknowledge professor Xian-rong $\mathrm{Xu}$, Dr Cheng Jiang, and Mrs Ting Xia for their involvement. This study was supported by Zhejiang Provincial Natural Science Foundation of China (LY14H280003) and Zhejiang Pharmaceutical Association (2012ZYY11).

\section{Disclosure}

The authors report no conflicts of interest in this work.

\section{References}

1. Decramer M, Janssens W, Miravitlles M. Chronic obstructive pulmonary disease. Lancet. 2012;379(9823):1341-1351.

2. GOLD. Global Initiative for Chronic Obstructive Lung Disease [updated January 18, 2015]. Available from: http://www.goldcopd.org/. Accessed January $15,2015$.

3. Zhong N, Wang C, Yao W, et al. Prevalence of chronic obstructive pulmonary disease in China: a large, population-based survey. $\mathrm{Am}$ J Respir Crit Care Med. 2007;176(8):753-760.

4. Chronic Obstructive Pulmonary Disease Study Group, Thoracic Society, Chinese Medical Association (CMACOPDS). [Guideline for diagnosis and treatment of COPD]. Zhonghua Jie He He Hu Xi Za Zhi. 2007; 30(1):8-17. Chinese.

5. Vestbo J, Anderson JA, Calverley PMA, et al. Adherence to inhaled therapy, mortality and hospital admission in COPD. Thorax. 2009; 64(11):939-943.

6. Ingebrigtsen TS, Marott JL, Nordestgaard BG, et al. Low use and adherence to maintenance medication in chronic obstructive pulmonary disease in the general population. J Gen Intern Med. 2015;30(1):51-59.

7. Carter BL, Rogers M, Daly J, Zheng S, James PA. The potency of team-based care interventions for hypertension: a meta-analysis. Arch Intern Med. 2009;169(19):1748-1755.

8. Collins C, Limone BL, Scholle JM, Coleman CI. Effect of pharmacist intervention on glycemic control in diabetes. Diabetes Res Clin Pract. 2011;92(2):145-152.

9. Hess LM, Raebel MA, Conner DA, Malone DC. Measurement of adherence in pharmacy administrative databases: a proposal for standard definitions and preferred measures. Ann Pharmacother. 2006; 40(7-8):1280-1288.

10. Khdour MR, Kidney JC, Smyth BM, McElnay JC. Clinical pharmacyled disease and medicine management programme for patients with COPD. Br J Clin Pharmacol. 2009;68(4):588-598.

11. Rodrigo GJ, Plaza V. Efficacy and safety of a fixed-dose combination of indacaterol and glycopyrronium for the treatment of COPD: a systematic review. Chest. 2014;146(2):309-317.

12. Nonato NL, Díaz O, Nascimento OA, Dreyse J, Jardim JR, Lisboa C. Behavior of quality of life (SGRQ) in COPD patients according to BODE scores. Arch Bronconeumol. 2015;51(7):315-321.

13. Welling JB, Hartman JE, Ten Hacken NH, Klooster K, Slebos DJ. The minimal important difference for the St George's Respiratory Questionnaire in patients with severe COPD. Eur Respir J. 2015;46(6): 1598-1604.

14. Brown P, Bluml BM, Kritzler R, et al. White paper on expanding the role of pharmacists in chronic obstructive pulmonary disease. $J \mathrm{Am}$ Pharm Assoc. 2011;51(2):203-211. 
15. Tommelein E, Tollenaere K, Mehuys E, Boussery K. Pharmaceutical care for patients with COPD in Belgium and views on protocol implementation. Int J Clin Pharm. 2014;36(4):697-701.

16. Spruit MA, Augustin IM, Vanfleteren LE, et al. Differential response to pulmonary rehabilitation in COPD: multidimensional profiling. Eur Respir J. 2015;46(6):1625-1635.

17. Burtin C, Ter Riet G, Puhan MA, et al. Handgrip weakness and mortality risk in COPD: a multicentre analysis. Thorax. 2016;71(1):86-87.

18. Jordan RE, Majothi S, Heneghan NR, et al. Supported self-management for patients with moderate to severe chronic obstructive pulmonary disease (COPD): an evidence synthesis and economic analysis. Health Technol Assess. 2015;19(36):1-516.
19. McGeoch GR, Willsman KJ, Dowson CA, et al. Self-management plans in the primary care of patients with chronic obstructive pulmonary disease. Respirology. 2006;11(5):611-618.

20. Criner GJ, Bourbeau J, Diekemper RL, et al. Prevention of acute exacerbations of COPD: American College of Chest Physicians and Canadian Thoracic Society Guideline. Chest. 2015;147(4):894-942.

21. Garcia-Aymerich J, Hernandez C, Alonso A, et al. Effects of an integrated care intervention on risk factors of COPD readmission. Respir Med. 2007;101(7):1462-1469.

22. Hansen RA, Kim MM, Song L, Tu W, Wu J, Murray MD. Comparison of methods to assess medication adherence and classify nonadherence. Ann Pharmacother. 2009;43(3):413-422.

\section{Publish your work in this journal}

Patient Preference and Adherence is an international, peer-reviewed, open access journal that focuses on the growing importance of patient preference and adherence throughout the therapeutic continuum. Patient satisfaction, acceptability, quality of life, compliance, persistence and their role in developing new therapeutic modalities and compounds to optimize clinical outcomes for existing disease states are major areas of interest for the journal. This journal has been accepted for indexing on PubMed Central. The manuscript management system is completely online and includes a very quick and fair peer-review system, which is all easy to use. Visit http://www. dovepress.com/testimonials.php to read real quotes from published authors.

\footnotetext{
Submit your manuscript here: http://www.dovepress.com/patient-preference-and-adherence-journal
} 